\title{
Altered expression of major immune regulatory molecules in peripheral blood immune cells associated with breast cancer
}

\author{
Kosuke Kawaguchi $^{1} \cdot$ Eiji Suzuki $^{1} \cdot$ Ayane Yamaguchi $^{1} \cdot$ Michio Yamamoto $^{2}$. \\ Satoshi Morita ${ }^{2} \cdot$ Masakazu Toi $^{1}$
}

Received: 30 December 2015/ Accepted: 18 February 2016/Published online: 4 March 2016

(c) The Author(s) 2016. This article is published with open access at Springerlink.com

\begin{abstract}
Background The purpose of this study was to clarify the alterations of major immune regulators in peripheral blood mononuclear cells (PBMCs) of cancer patients and to analyze the association with the disease progression in breast cancer patients.

Methods The study included 6 healthy volunteers (HVs), 12 primary breast cancer (PBC) patients, and 30 metastatic breast cancer $(\mathrm{MBC})$ patients. The expression of immune regulators such as, CCR6, $C D 4, C D 8, C D 14, C D 40, C D 56$, CD80, CTLA4, CXCR4, FOXP3, IDO-1, IDO-2, NKG2D, $N R P-1, P D-1$, and $P D-L 1$ mRNA in PBMCs was measured by quantitative RT-PCR. Analysis of variance with contrasts was performed to find expression patterns of the three groups (HVs, PBC, MBC).

Results We clarified the alterations of mRNA of major immune regulators $P D-L 1, F O X P 3, C D 80, C D 40$, and $C D 14$ in PBMCs of cancer patients and the association of these alternations with disease progression. Furthermore, $P D-L 1$ expression was correlated with serum interferon- $\gamma$ production.

Conclusion Our data suggested that mRNA expressions of PD-L1, FOXP3, CD80, CD40 and CD14 in PBMCs are affected by disease progression. Understanding the roles of these various interactions will be of importance to future
\end{abstract}

Eiji Suzuki

eijis@kuhp.kyoto-u.ac.jp

1 Department of Breast Surgery, Graduate School of Medicine, Kyoto University, 54 Shogoin-kawaharacho, Sakyo-ku, Kyoto 606-8507, Japan

2 Department of Biomedical Statistics and Bioinformatics, Kyoto University, Kyoto, Japan studies aiming to uncover biomarkers for predicting response to immune therapy.

Keywords Breast cancer - PD-1 - CD80 - PD-L1 - CD40 and PBMCs

\section{Introduction}

Recent clinical data have emphatically shown the capacity of our immune systems to eradicate even advanced cancers. Comparably high response rates were reported in initial clinical trials evaluating inhibitors of the immune checkpoint, such as anti-PD-L1, anti-PD-1, and anti-CTLA4, in various cancers [1-6]. However, the objective response rate to inhibitors of the immune checkpoint was $30-40 \%$ and it was unclear which biomarkers could be used to predict the clinical response to immune checkpoint inhibitors. Thus, biomarker analysis of immune checkpoint inhibitors is a research priority.

Recent biomarker analysis showed mismatch repairdeficient tumors and tumor-specific neoantigen load were highly responsive to checkpoint blockade with anti-PD-1 [7]. Other studies suggested that hypermutated tumors might harbor additional tumor-specific neoantigens and increased amounts of tumor-infiltrating lymphocytes (TILs) [8-10]. Thus, PD-L1 expression by TILs rather than tumor cells is more predictive of the response to blockade of the PD-1 pathway $[11,12]$. Although these biomarkers are meaningful, they have problems of assay complexity with respect to clinical usage, cost, repeatability, and heterogeneity.

The purpose of this study was to confirm that peripheral blood immune cells, and not immune cells, in tumor tissue can be used to evaluate immune checkpoint-related gene 
expression in terms of the correlation of expression level with the clinical status of breast cancer. We prospectively validated PBMCs in healthy volunteers (HVs), primary breast cancer $(\mathrm{PBC})$ patients, and metastatic breast cancer (MBC) patients. At the molecular level, the mRNA expression levels of 16 immune genes were measured in PBMCs, including putative immunosuppressive factors (IDO-1, PD-1, PD-L1, CTLA4, and FOXP3). The rationale for marker selection was to include $\mathrm{T}$ cell markers, chemokines, and immune checkpoint markers that are currently under evaluation as therapeutic targets.

\section{Materials and methods}

\section{Study design and outcomes}

We screened 16 genes (CD80, CTLA4, IDO-1, IDO-2, PD1, PD-L1, CD56, FOXP3, NKG2D, NRP-1, CD4, CD8, $C D 40, C C R 6, C D 14$, and $C X C R 4)$ in PBMCs by quantitative real time-PCR (qRT-PCR). Expression patterns were defined as non-specific, breast cancer (BC)-specific, MBCspecific, and linear by ANOVA (details of statistical analysis are described below). Representative box plots of non-specific, BC-specific, MBC-specific, and linear expression patterns are presented in Fig. 1.

\section{Human tissue samples}

All samples from HVs and BC patients were collected in the Department of Breast Surgery, Kyoto University Hospital. In PBC patients, PBMCs and serum were collected at the diagnosis. In MBC patients, PBMCs and serum were collected at the diagnosis of primary metastasis or during therapy for metastasis. Written informed consent was given by all participants prior to collection. All study protocols were approved by the Ethics Committee for Clinical Research, Kyoto University Hospital (authorization number G424) and were in keeping with the provisions of the Declaration of Helsinki in 1995.

\section{PBMC isolation and RNA extraction}

PBMCs were prepared using BD Vacutainer CPT Cell Preparation Tubes (BD, Franklin Lakes, NJ, USA). The blood processing reported below was according to the
Fig. 1 Representative examples of box plots of four expression patterns. a Nonspecific pattern. b Breast cancer-specific pattern. c Metastatic breast cancerspecific pattern. $\mathbf{d}$ Linear pattern

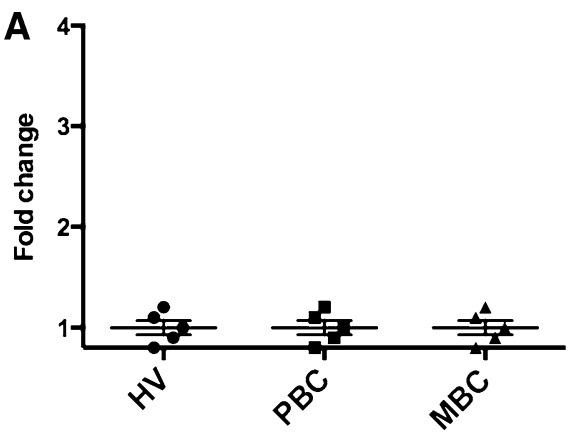

Non-Specific Pattern

C

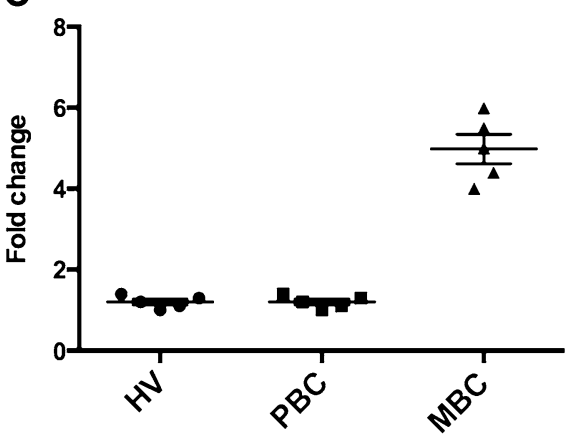

Metastatic Breast Cancer-Specific Pattern (MBC-Specific Pattern)

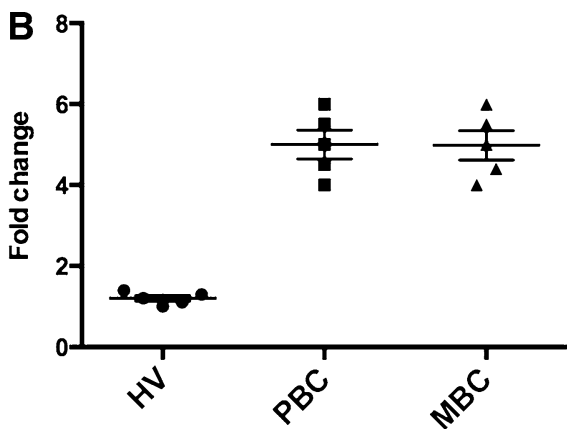

Breast Cancer-Specific Pattern

(BC-Specific Pattern)

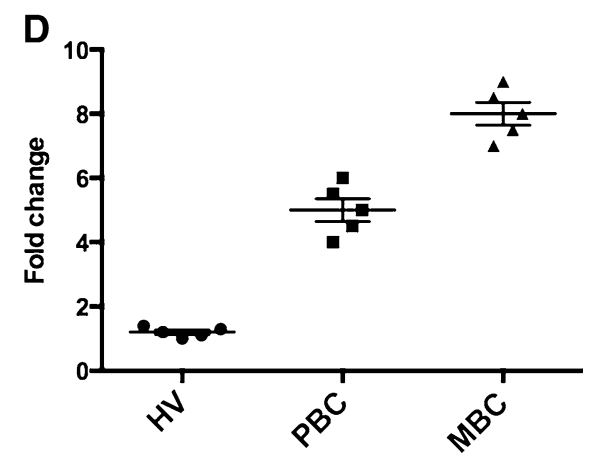

Linear Pattern 
manufacturer's instructions. The tubes were centrifuged at room temperature for $20 \mathrm{~min}$ in a horizontal rotor at 1800 relative centrifugal force (RCF) within $1 \mathrm{~h}$ of blood collection. The plasma layer and the cells from both CPT tubes were transferred to one conical centrifuge tube. Phosphate-buffered saline was added to a final volume of $2 \mathrm{~mL}$, the tubes were capped, and the cells were mixed by inversion. Subsequently, the tubes were centrifuged for $10 \mathrm{~min}$ at $4{ }^{\circ} \mathrm{C}$ and $1500-1800 \mathrm{RCF}$. The supernatant was aspirated and $1 \mathrm{~mL} \mathrm{TRIzol}{ }^{\circledR}$ reagent (Invitrogen, Carlsbad, CA, USA) was added to isolate total RNA according to the manufacturer's instructions. Total RNA was frozen immediately in liquid nitrogen and stored at $-80{ }^{\circ} \mathrm{C}$. The quality of total RNA was determined using microfluidic electrophoresis (Bioanalyzer; Agilent Technologies, Palo Alto, CA, USA).

\section{qRT-PCR}

qRT-PCR was performed with TaqMan Fast Virus 1-step master mix (Life Technologies Carlsbad, CA, USA) and TaqMan Gene Expression probes for CD80 (Assay ID: Hs01045163_m1), CTLA4 (Assay ID: Hs00175480_m1), IDO-1 (Assay ID: Hs00984148_m1), IDO-2 (Assay ID: Hs01589373_m1), PD-1 (Assay ID: Hs01550088_m1), PD-L1 (Assay ID: Hs01125301_m1), CD56 (Assay ID: Hs00941830_m1), FOXP3 (Assay ID: Hs01085834_m1), NKG2D (Assay ID: Hs00183683_m1), NRP-1 (Assay ID: Hs00826128_m1), CD4 (Assay ID: Hs01058407_m1), CD8 (Assay ID: Hs00233520_m1), CD40 (Assay ID: Hs01002913_g1), CCR6 (Assay ID: Hs01890706_s1), CD14 (Assay ID: Hs02621496_s1), and CXCR4 (Assay ID: Hs00607978_s1) (Life Technologies).

\section{Cytokine measurement}

The cytokines in serum-interferon (IFN)- $\gamma$, transforming growth factor (TGF)- $\beta 1$, TGF- $\beta 2$, and TGF- $\beta 3$-were measured using a Bio-Plex multiplex assay system (BioRad, Hercules, CA, USA) according to the manufacturer's instructions.

\section{Statistical analysis}

All mRNA expression levels were normalized by their mean expression levels in HVs. ANOVA with contrasts was performed to find expression patterns of the three groups ( $\mathrm{HV}, \mathrm{PBC}, \mathrm{MBC})$. The coefficients of the contrasts for group means were as follows: $(-1.0,0.5,0.5)$ for $\mathrm{BC}$ specific type, $(-0.5,-0.5,1.0)$ for $\mathrm{MBC}$-specific type, and $(-1.0,0.0,1.0)$ for linear type. A gene that was non-significant for all contrasts was classified as non-specific type. Pearson correlation coefficients between expressions in
PBMCs (PD-L1 and FOXP3) and cytokine levels in serum in MBC patients were calculated. Subgroup analysis in MBC was performed by Student's $t$ test. Each hypothesis was tested at the $5 \%$ significance level. ANOVA was performed by using SAS version 9.3 software. Pearson correlation coefficient and Student's $t$ test were performed using STATA version 13.0.

\section{Results}

\section{Patients' characteristics}

The characteristics of the patients are presented in Table 1. Peripheral blood samples were taken from $42 \mathrm{BC}$ patients and $6 \mathrm{HVs}$. Twelve patients were PBC $(28.6 \%)$ and 30 patients were MBC $(71.4 \%)$. The main phenotype was luminal type, $58.3 \%$ in $\mathrm{PBC}$ and $73.3 \%$ in MBC. In $\mathrm{MBC}$, the main metastatic type was visceral metastasis $(76.7 \%)$. Nine patients $(30.0 \%)$ had one metastatic site, seven patients $(23.3 \%)$ had two metastatic sites, twelve patients $(40.0 \%)$ had three metastatic sites and two patients $(6.7 \%)$ had four metastatic sites. About a half of patients $(46.7 \%)$ was received endocrine therapy and all HER2 positive patients were received anti-HER2 therapy.

\section{mRNA expression levels in PBMCs}

Tables 2 shows the mRNA expression levels in PBMCs. All data were normalized by the mRNA expression levels of HVs. By statistical analysis, CD80 ( $p=0.039)$ was the only gene defined as BC-specific. CD14 $(p=0.046)$ and $C D 40(p=0.013)$ were defined as MBC-specific, while PD-L1 $(p=0.027)$ and FOXP3 $(p=0.015)$ were defined as linear. $P D-L 1 \quad(p=0.003)$ and FOXP3 $(p=0.002)$ were also defined as MBC-specific. The mRNA levels of $P D-L 1$ and FOXP3 in MBC were 2.54- and 2.94-fold compared with HVs, respectively. Representative box plot figures of non-specific, BC-specific, MBC-specific, and linear expression patterns are shown in Fig. 2a, b, c, d.

\section{Subgroup analysis of CD80, PD-L1, FOXP3, CD40 and $C D 14$ mRNA expression in MBC patients}

The condition of host immune cells may be affected by various factors. Thus, we checked how CD80, PD-L1, FOXP3, CD40 and CD14 expression was affected by age, number of metastatic sites and therapeutic status in MBC patients. Table 3 shows results of subgroup analysis in MBC patients. There were no factors, which affect $C D 80$, $P D-L 1, F O X P 3$ and CD14 expression in PBMCs in MBC patients. In CD40 expression, patients who received antiHER2 therapy was significantly decreased compared with 
Table 1 Patients' characteristics

\begin{tabular}{|c|c|c|c|c|c|}
\hline Characteristic & No. & $\%$ & Characteristic & No. & $\%$ \\
\hline All & 42 & 100 & & & \\
\hline Primary breast cancer (PBC) & 12 & 28.6 & & & \\
\hline Metastatic breast cancer (MBC) & 30 & 71.4 & & & \\
\hline PBC & & & $\mathrm{MBC}$ & & \\
\hline PBC ALL & 12 & 100 & MBC ALL & 30 & 100 \\
\hline Age (median, range) & 54.5 & $35-78$ & Age (median, range) & 61 & $43-80$ \\
\hline Stage & & & Type of metastasis & No. & $\%$ \\
\hline DCIS & 3 & 25.0 & Visceral & 23 & 76.7 \\
\hline I & 1 & 8.3 & Non-visceral & 7 & 23.3 \\
\hline II & 6 & 50.0 & Number of metastatic sites & No. & $\%$ \\
\hline III & 4 & 33.3 & 1 & 9 & 30.0 \\
\hline Phenotype & & & 2 & 7 & 23.3 \\
\hline Luminal & 7 & 58.3 & 3 & 12 & 40.0 \\
\hline HER2 & 3 & 25.0 & 4 & 2 & 6.7 \\
\hline \multirow[t]{10}{*}{ TNBC } & 1 & 8.3 & Therapeutic status & No. & $\%$ \\
\hline & & & Endocrine therapy & 14 & 46.7 \\
\hline & & & Anthracycline & 1 & 3.3 \\
\hline & & & Taxan & 9 & 30.0 \\
\hline & & & $5 \mathrm{FU}$ & 4 & 13.3 \\
\hline & & & Ant-HER2 therapy & 7 & 23.3 \\
\hline & & & Phenotype & & \\
\hline & & & Luminal & 21 & 70.0 \\
\hline & & & HER2 & 7 & 23.3 \\
\hline & & & Triple negative & 2 & 6.7 \\
\hline
\end{tabular}

Table 2 mRNA expression levels in PBMCs

\begin{tabular}{|c|c|c|c|c|c|c|c|}
\hline \multirow[t]{2}{*}{ Gene name } & \multicolumn{3}{|c|}{ Fold change (mean $\pm \mathrm{SD}$ ) } & \multicolumn{3}{|c|}{ ANOVA ( $p$ value) } & \multirow[t]{2}{*}{ Type } \\
\hline & HV & $\mathrm{PBC}$ & $\mathrm{MBC}$ & BC specific & MBC specific & Linear & \\
\hline$C D 80$ & $1.000 \pm 0.171$ & $2.192 \pm 0.454$ & $1.960 \pm 0.187$ & 0.039 & 0.308 & 0.066 & BC-specifc \\
\hline CTLA4 & $1.000 \pm 0.162$ & $1.651 \pm 0.480$ & $1.532 \pm 0.132$ & 0.195 & 0.515 & 0.248 & Non-specific \\
\hline IDOI & $1.000 \pm 0.140$ & $1.935 \pm 0.519$ & $1.297 \pm 0.202$ & 0.277 & 0.665 & 0.602 & Non-specific \\
\hline IDO2 & $1.000 \pm 0.449$ & $0.777 \pm 0.273$ & $0.669 \pm 0.142$ & 0.472 & 0.416 & 0.396 & Non-specific \\
\hline$P D 1$ & $1.000 \pm 0.217$ & $0.659 \pm 0.134$ & $0.749 \pm 0.121$ & 0.275 & 0.670 & 0.359 & Non-specific \\
\hline PDL1 & $1.000 \pm 0.085$ & $1.188 \pm 0.355$ & $2.540 \pm 0.313$ & 0.201 & 0.003 & 0.027 & Linear \\
\hline$C D 56$ & $1.000 \pm 0.214$ & $1.481 \pm 0.427$ & $1.757 \pm 0.253$ & 0.303 & 0.221 & 0.214 & Non-specific \\
\hline FOXP3 & $1.000 \pm 0.129$ & $1.330 \pm 0.298$ & $2.944 \pm 0.373$ & 0.142 & 0.002 & 0.015 & Linear \\
\hline$N K G 2 D$ & $1.000 \pm 0.131$ & $0.768 \pm 0.175$ & $1.323 \pm 0.147$ & 0.886 & 0.055 & 0.320 & Non-specific \\
\hline$N R P 1$ & $1.000 \pm 0.287$ & $2.185 \pm 0.601$ & $1.447 \pm 0.305$ & 0.286 & 0.784 & 0.561 & Non-specific \\
\hline$C D 4$ & $1.000 \pm 0.098$ & $1.196 \pm 0.116$ & $1.143 \pm 0.054$ & 0.236 & 0.652 & 0.322 & Non-specific \\
\hline CD8 & $1.000 \pm 0.319$ & $0.655 \pm 0.087$ & $0.886 \pm 0.073$ & 0.245 & 0.668 & 0.567 & Non-specific \\
\hline$C D 40$ & $1.000 \pm 0.096$ & $1.205 \pm 0.122$ & $1.424 \pm 0.103$ & 0.167 & 0.046 & 0.068 & MBC-specific \\
\hline CCR6 & $1.000 \pm 0.648$ & $1.075 \pm 0.616$ & $0.744 \pm 0.116$ & 0.874 & 0.464 & 0.658 & Non-specific \\
\hline$C D 14$ & $1.000 \pm 0.115$ & $1.089 \pm 0.186$ & $1.680 \pm 0.165$ & 0.282 & 0.013 & 0.063 & MBC-specific \\
\hline CXCR4 & $1.000 \pm 0.255$ & $1.272 \pm 0.287$ & $1.173 \pm 0.168$ & 0.618 & 0.720 & 0.621 & Non-specific \\
\hline
\end{tabular}

All mRNA expression levels were normalized by their mean expression levels in HVs. ANOVA with contrasts was performed to find expression patterns of the three groups (HV, PBC, MBC). The coefficients of the contrasts for group means were as follows: $(-1.0,0.5,0.5)$ for BC-specific type, $(-0.5,-0.5,1.0)$ for MBC-specific type, and $(-1.0,0.0,1.0)$ for linear type. Each hypothesis was tested at the $5 \%$ significance level. Bold font represents significant genes by ANOVA 
Fig. 2 Represent figures of mRNA expression levels in PBMCs. These data show the mRNA expression levels in PBMCs by quantitative realtime-PCR. All data are normalized by the mRNA expression levels of healthy volunteers (mean 1.00). a Nonspecific pattern: $C D 4, C D 8, P D$ 1 , and CTLA4. b Breast cancerspecific pattern: $C D 80$.

c Metastatic breast cancerspecific pattern: $C D 14$ and CD40. d Linear pattern: $P D-L 1$ and FOXP3. All bars show mean \pm SEM
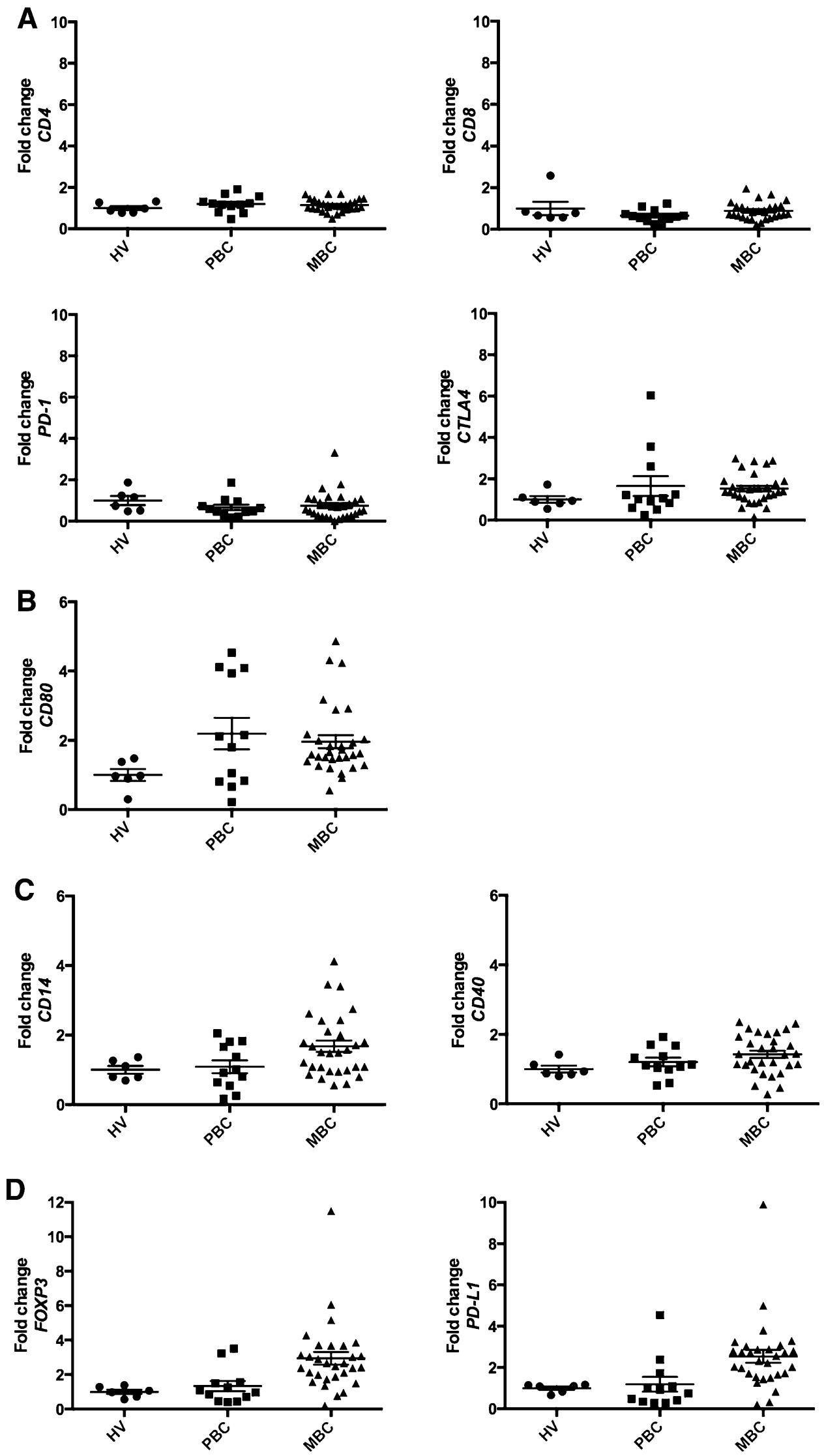


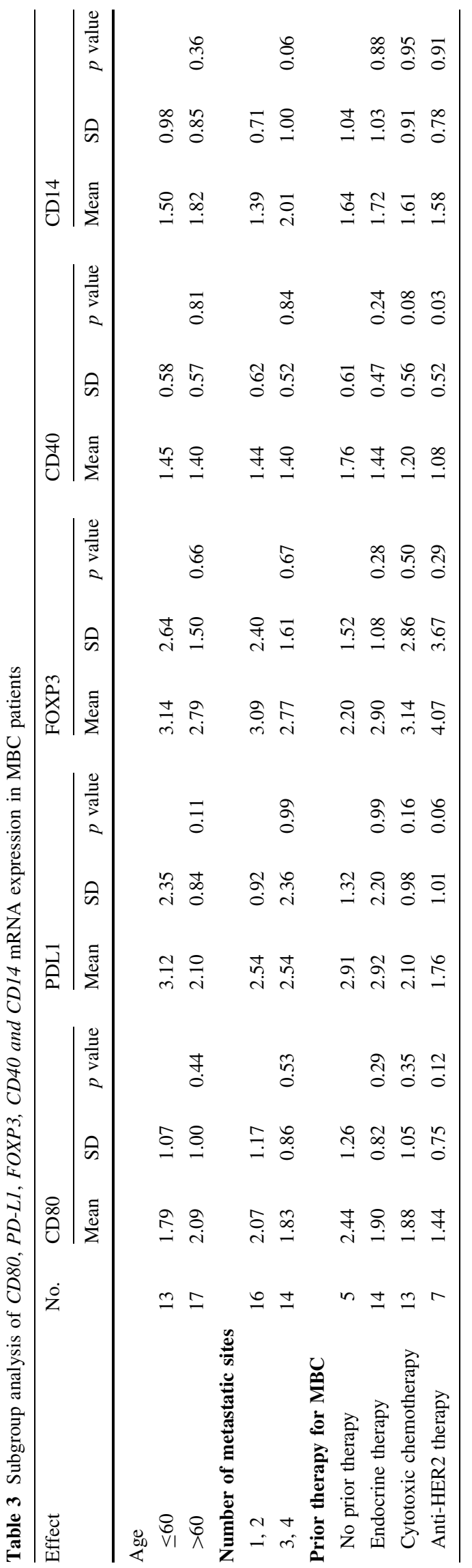

Fig. 3 Correlation between $P D-L 1$ and FOXP3 expression in PBMCs and interferon (IFN)- $\gamma$ and transforming growth factor (TGF)- $\beta$ levels in serum. a Correlation between $P D-L 1$ in PBMCs and IFN- $\gamma$ and TGF- $\beta 1-3$ in serum. b Correlation between FOXP3 in PBMCs and IFN- $\gamma$ and TGF- $\beta 1-3$ in serum. $R$ coefficient correlation value

patients who received no prior therapy (mean mRNA levels 1.08 vs. $1.76, p=0.03$ ).

\section{Correlation between $P D-L 1$ and $F O X P 3$ expression in PBMCs and IFN- $\gamma$ and TGF- $\beta$ serum levels}

We checked the correlation between $P D-L 1$ expression in PBMCs and cytokine levels in the serum of MBC patients. $P D-L 1$ expression correlated with IFN- $\gamma(R=0.52$, $p=0.01)$, but did not correlate with TGF- $\beta 1(R=0.098$, $p=0.66)$, TGF- $\beta 2(R=-0.16, p=0.48)$, or TGF- $\beta 3$ $(R=0.15, \quad p=0.51) \quad$ (Fig. 3a). Conversely, FOXP3 expression correlated with TGF- $\beta 2 \quad(R=-0.45$, $p=0.03)$, but did not correlate with IFN- $\gamma(R=0.39$, $p=0.067)$, TGF- $\beta 1(R=-0.025, p=0.91)$, or TGF- $\beta 3$ $(R=-0.016, p=0.94)$ (Fig. 3b).

\section{Discussion}

Recently, biomarker analysis of immune cells was reported in the cancer microenvironment: TILs by immunohistochemistry, tumor digestion, and gene expression analysis of formalin-fixed and paraffin-embedded tissue samples, and flow cytometry analysis of immune checkpoint-related protein expression including inhibitory and activation molecules [13-16]. Additionally, PD-L1 expression by TILs rather than tumor cells was shown to be more predictive of the response to PD-1 pathway blockade [11, 12]. Thus, biomarker analysis has become increasingly importantly especially in immunotherapy to cancer. In this study, we prospectively validated PBMCs by qRT-PCR because PBMCs can be collected in a less invasive manner than tumor biopsy and can be compared quantitatively to other types of immune analysis. In fact, we show here that upregulation of the mRNA expression levels of $P D-L 1$, FOXP3, CD80, CD40, and CD14 in PBMCs is associated with breast cancer. In addition, we found that the expression of these genes in PBMCs could be used to define three types of up-regulation: $C D 80$ was BC-specific, $C D 40$ and $C D 14$ were MBC-specific, and $P D-L 1$ and FOXP3 were linear (Fig. 4).

The development of human cancer is a multistep process characterized by the accumulation of genetic and epigenetic alterations that drive or reflect tumor progression. These changes distinguish cancer cells from their normal counterparts, allowing tumors to be recognized as 


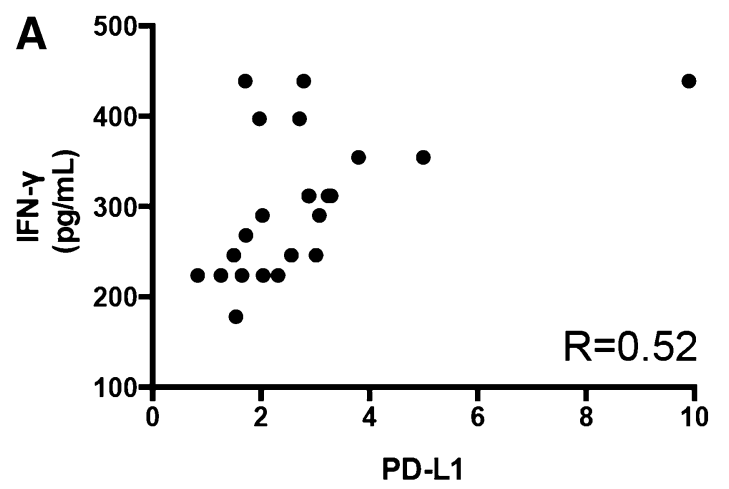

(Fold change)

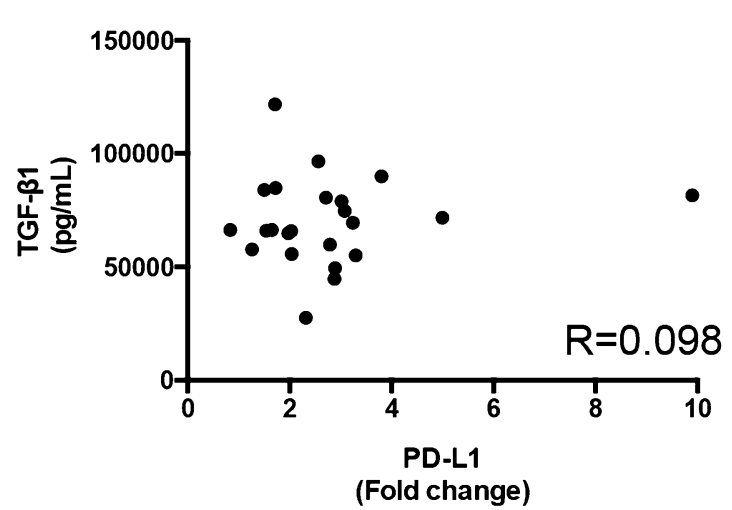

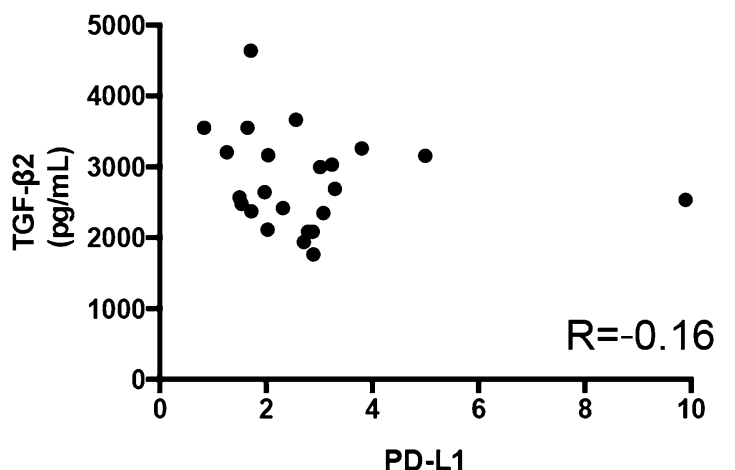

(Fold change)

B
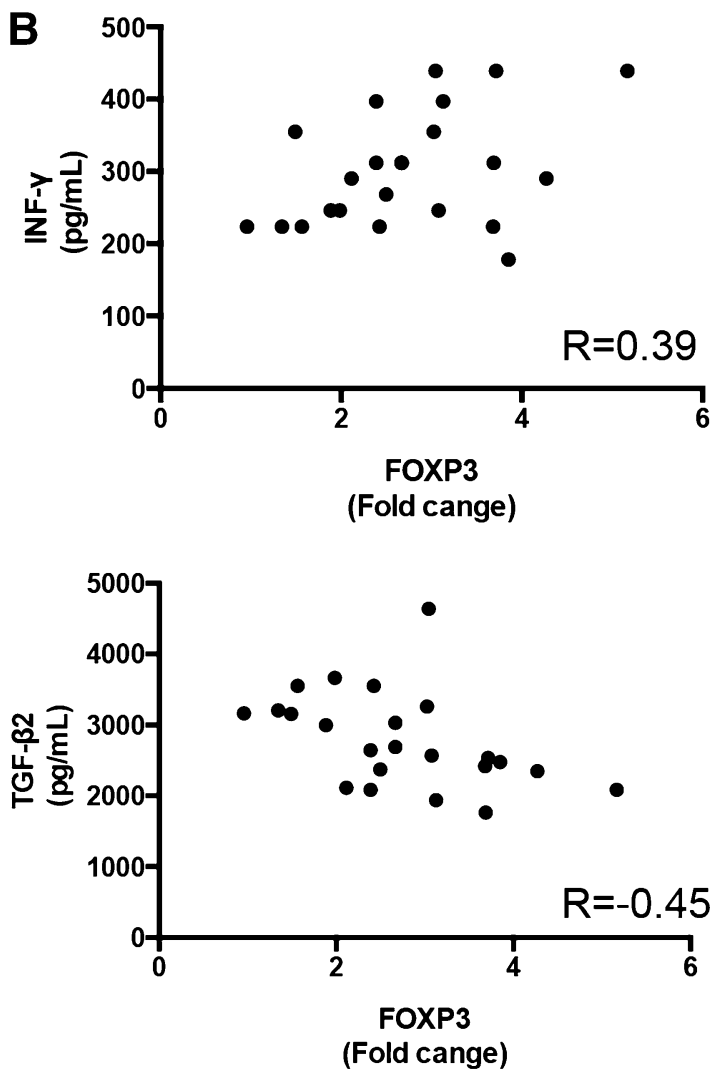
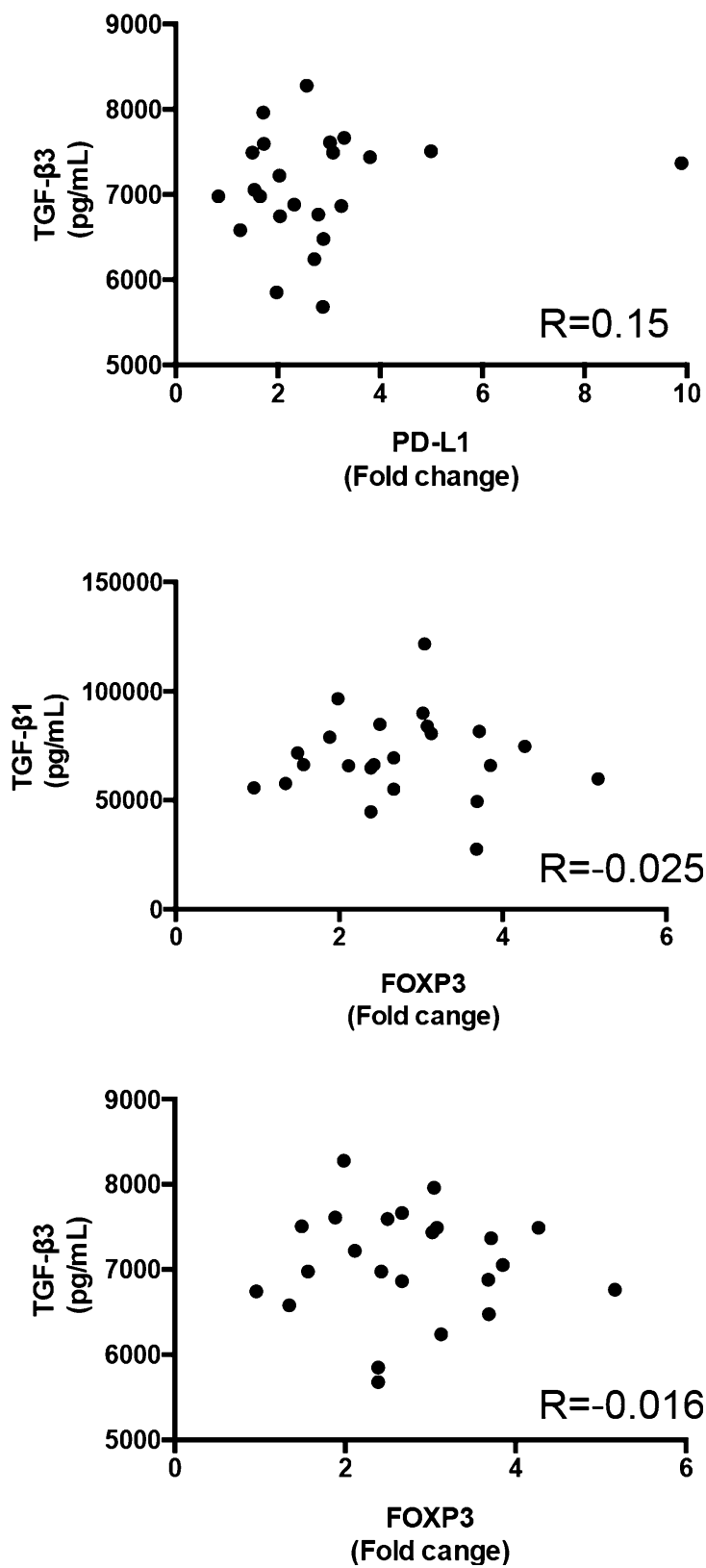
Fig. 4 Graphical abstract of this study. $A P C$ antigenpresenting cells, $P B C$ primary breast cancer, $M B C$ metastatic breast cancer

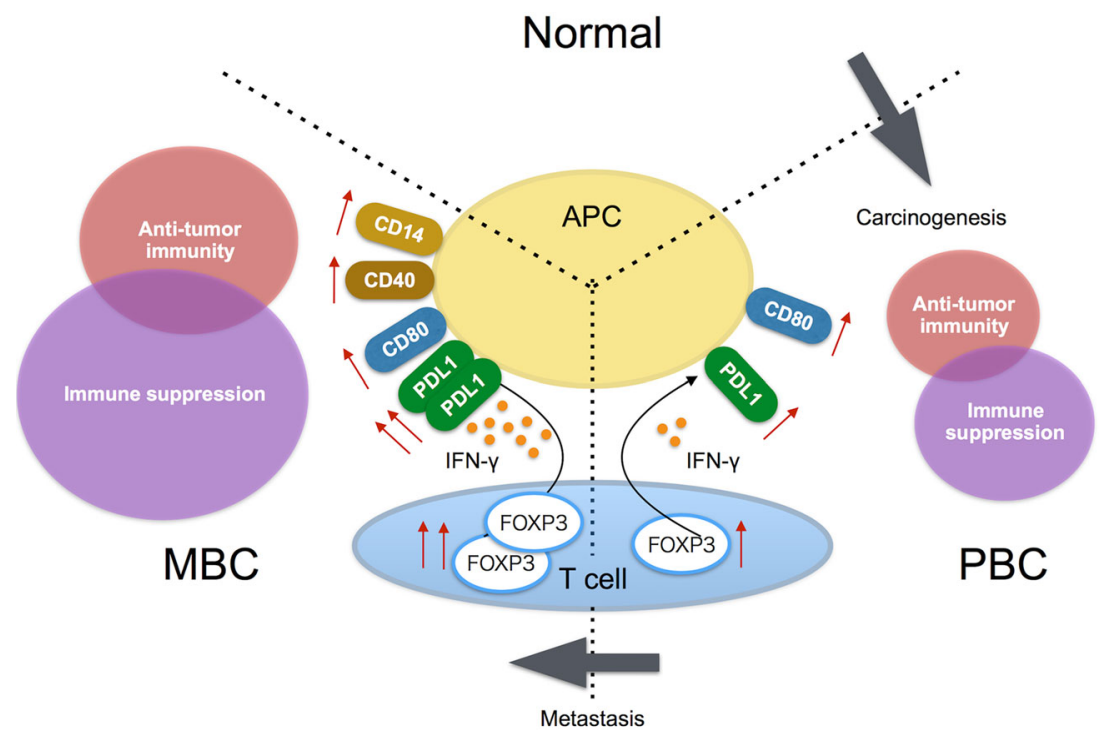

foreign by the immune system [17-19]. However, tumors are rarely rejected spontaneously, reflecting their ability to maintain an immunosuppressive microenvironment [20]. Immune checkpoint pathways strongly down-regulate $\mathrm{T}$ cell activation with the intent of keeping nascent $\mathrm{T}$ cell responses in check and reducing the likelihood of an immune attack against normal tissues. The myriad of genetic and epigenetic alterations that are characteristic of all cancers provide a diverse set of antigens that the immune system can use to distinguish tumor cells from their normal counterparts. In the case of T cells, the ultimate amplitude and quality of the response, which is initiated through antigen recognition by the $\mathrm{T}$ cell receptor, is regulated by a balance between co-stimulatory and inhibitory signals [21].

CD40, a tumor necrosis factor receptor superfamily member, is primarily expressed on antigen-presenting cells (APCs), such as dendritic cells and monocytes [22]. A recent report showed that anti-CD40 treatment induces PDL1 up-regulation on tumor-infiltrating monocytes and macrophages, which was strictly dependent on $\mathrm{T}$ cells and IFN- $\gamma$ [23]. Our data showed the up-regulation of $C D 40$, $C D 14$, and $P D-L 1$ in MBC (Fig. 2). These findings suggest that APCs are activated by neoantigens from a metastatic breast tumor and their activation leads to the activation of the checkpoint pathway, such as the up-regulation of $P D$ $L 1$ expression. In fact, $P D-L 1$ expression was correlated with IFN- $\gamma$ levels in MBC (Fig. 3); thus, our gene expression analysis of PBMCs might reflect immune elimination and immune escape in the breast cancer microenvironment of the peripheral blood.

CD80 was found on activated APCs that provide a costimulatory signal necessary for $\mathrm{T}$ cell activation and survival. It is the ligand for two different proteins on the $\mathrm{T}$ cell surface: CD28 and CTLA4 [24]. CTLA4 interacts with both CD80 and CD86 with higher affinity and avidity than does CD28, with the CTLA4-CD80 interaction being the strongest and the CD28-CD86 interaction being the weakest [25]. Therefore, up-regulation of CD80 may indicate T cell tolerance in the breast tumor microenvironment, $\mathrm{CD} 80$ has the potential to be used as a CD80/CD86-CTLA4 pathway blocking therapy. However, in autoimmune diseases, the superior affinity of CTLA4 for its ligands led to the use of a CTLA4-immunoglobulin fusion protein (CTLA4-Ig) as an inhibitor of immune responses in vivo; the rationale being that it would bind to CD80 and CD86 and block their interaction with $\mathrm{CD} 28$ [26, 27]. Further investigation is required in vivo and in translational research of CD80 function in the cancer microenvironment.

The innate resistance of tumor cells to T cells is caused by activation of the AKT pathway, which leads to the upregulation of PD-L1 expression on tumor cells [28]. On another front, adaptive resistance is generated by IFN- $\gamma$ induced PD-L1 expression on either tumor cells themselves or on immune cells (macrophages, myeloid suppressor cells, dendritic cells, or even lymphocytes) in the tumor microenvironment. Previous reports suggested that the upregulation of PD-L1 and regulatory $\mathrm{T}$ cells in the cancer microenvironment in vivo depended on IFN- $\gamma$ levels $[23$, 29]. Our data also showed that $P D-L 1$ and FOXP 3 were upregulated in PBMCs in a linear pattern and correlated with IFN- $\gamma$ serum levels (Figs. 2d, 3). These data indicate that up-regulation of $P D-L 1$ and FOXP3 in PBMCs may be a result of adaptive resistance to $\mathrm{T}$ cells and their expression is regulated by IFN- $\gamma$ levels in the breast cancer microenvironment.

This is the first report to demonstrate that the expression of immune genes in PBMCs is associated with breast tumor 
burden. In addition, one of the strong points of our research is that our samples were very high quality, as mRNA was extracted from PBMCs within $1 \mathrm{~h}$ from blood collection, and then preserved at a low temperature. Almost all previous studies preserved PBMCs before total RNA was extracted, regardless of the fact that the characteristics of PBMCs can be changed easily in the time from blood collection to freezing [6].

Our study is limited in that we performed gene expression analysis in PBMCs and not in a specific immune cell subset. However, from the clinical point of view, the study of PBMCs rather than the isolation of immune cell subsets requires less technical complexity and less sample processing time; although from an immunological point of view, gene expression analysis of specific immune cell subsets is more interesting and important. Another limitation of the current study is that we focused our attention on 16 major immune regulatory genes because they are associated with the immune checkpoint pathway and are therefore candidates for inhibiting $\mathrm{T}$ cell function at the tumor site. Several other candidate inhibitory mechanisms have been described, including the secretion of cytokines, such as TGF- $\beta$, interleukin (IL-4), and IL-10. Although we have not found these to be associated with $P D-L 1$ or FOXP3 expression in PBMCs in breast cancer metastases, these factors could nonetheless contribute to immune evasion. This study is a plot setting to evaluate mRNA expression in PBMCs in breast cancer patients and sample size calculation was performed without various factors that may influence immune status such as cancer phenotype, therapeutic status and metastatic status. To overcome these limitations, we have started analysis of PBMCs in breast cancer by RNA sequencing as our next research project.

In conclusion, our data showed that the mRNA expression levels of PD-L1, FOXP3,CD80,CD40, and $C D 14$ in PBMCs were associated with breast cancer burden. Understanding the roles of these various interactions in breast cancer may become highly relevant for the development of immunomodulatory drugs and the discovery of biomarkers predictive of therapeutic response.

Acknowledgments We thank the medical staff of the Department of Breast Surgery of Kyoto University Hospital for their help in the recruitment of patients and collection of samples.

\section{Compliance with ethical standards}

Conflict of interest This study received no external funding. The authors have no conflict of interest.

Open Access This article is distributed under the terms of the Creative Commons Attribution 4.0 International License (http://crea tivecommons.org/licenses/by/4.0/), which permits unrestricted use, distribution, and reproduction in any medium, provided you give appropriate credit to the original author(s) and the source, provide a link to the Creative Commons license, and indicate if changes were made.

\section{References}

1. Brahmer J, Reckamp KL, Baas P, Crino L, Eberhardt WE, Poddubskaya E, et al. Nivolumab versus Docetaxel in advanced squamous-cell non-small-cell lung cancer. $\mathrm{N}$ Engl J Med. 2015;373:123-35.

2. Brahmer JR, Tykodi SS, Chow LQ, Hwu WJ, Topalian SL, Hwu $\mathrm{P}$, et al. Safety and activity of anti-PD-L1 antibody in patients with advanced cancer. N Engl J Med. 2012;366:2455-65.

3. Hodi FS, O'Day SJ, McDermott DF, Weber RW, Sosman JA, Haanen JB, et al. Improved survival with ipilimumab in patients with metastatic melanoma. N Engl J Med. 2010;363:711-23.

4. Motzer RJ, Escudier B, McDermott DF, George S, Hammers HJ, Srinivas $\mathrm{S}$, et al. Nivolumab versus Everolimus in advanced renal-cell carcinoma. N Engl J Med. 2015;373:1803-13.

5. Wolchok JD, Kluger H, Callahan MK, Postow MA, Rizvi NA, Lesokhin AM, et al. Nivolumab plus ipilimumab in advanced melanoma. N Engl J Med. 2013;369:122-33.

6. Campbell DE, Tustin NB, Riedel E, Tustin R 3rd, Taylor J, Murray J, et al. Cryopreservation decreases receptor PD-1 and ligand PD-L1 coinhibitory expression on peripheral blood mononuclear cell-derived $\mathrm{T}$ cells and monocytes. Clin Vaccine Immunol. 2009;16:1648-53.

7. Le DT, Uram JN, Wang H, Bartlett BR, Kemberling H, Eyring $\mathrm{AD}$, et al. PD-1 Blockade in tumors with mismatch-repair deficiency. N Engl J Med. 2015;372:2509-20.

8. Brown SD, Warren RL, Gibb EA, Martin SD, Spinelli JJ, Nelson $\mathrm{BH}$, et al. Neo-antigens predicted by tumor genome meta-analysis correlate with increased patient survival. Genome Res. 2014;24:743-50.

9. Rooney MS, Shukla SA, Wu CJ, Getz G, Hacohen N. Molecular and genetic properties of tumors associated with local immune cytolytic activity. Cell. 2015;160:48-61.

10. Rutledge WC, Kong J, Gao J, Gutman DA, Cooper LA, Appin C, et al. Tumor-infiltrating lymphocytes in glioblastoma are associated with specific genomic alterations and related to transcriptional class. Clin Cancer Res. 2013;19:4951-60.

11. Herbst RS, Soria JC, Kowanetz M, Fine GD, Hamid O, Gordon MS, et al. Predictive correlates of response to the anti-PD-L1 antibody MPDL3280A in cancer patients. Nature. 2014;515:563-7.

12. Powles T, Eder JP, Fine GD, Braiteh FS, Loriot Y, Cruz C, et al. MPDL3280A (anti-PD-L1) treatment leads to clinical activity in metastatic bladder cancer. Nature. 2014;515:558-62.

13. Denkert C, von Minckwitz G, Brase JC, Sinn BV, Gade S, Kronenwett R, et al. Tumor-infiltrating lymphocytes and response to neoadjuvant chemotherapy with or without carboplatin in human epidermal growth factor receptor 2-positive and triplenegative primary breast cancers. J Clin Oncol. 2015;33:983-91.

14. Graw S, Meier R, Minn K, Bloomer C, Godwin AK, Fridley B, et al. Robust gene expression and mutation analyses of RNAsequencing of formalin-fixed diagnostic tumor samples. Sci Rep. 2015;5:12335.

15. Keir ME, Liang SC, Guleria I, Latchman YE, Qipo A, Albacker LA, et al. Tissue expression of PD-L1 mediates peripheral T cell tolerance. J Exp Med. 2006;203:883-95.

16. Myklebust JH, Irish JM, Brody J, Czerwinski DK, Houot R, Kohrt HE, et al. High PD-1 expression and suppressed cytokine signaling distinguish $\mathrm{T}$ cells infiltrating follicular lymphoma tumors from peripheral T cells. Blood. 2013;121:1367-76. 
17. Chen DS, Irving BA, Hodi FS. Molecular pathways: next-generation immunotherapy-inhibiting programmed death-ligand 1 and programmed death-1. Clin Cancer Res. 2012;18:6580-7.

18. Mellman I, Coukos G, Dranoff G. Cancer immunotherapy comes of age. Nature. 2011;480:480-9.

19. van Rooij N, van Buuren MM, Philips D, Velds A, Toebes M, Heemskerk B, et al. Tumor exome analysis reveals neoantigenspecific T-cell reactivity in an ipilimumab-responsive melanoma. J Clin Oncol. 2013;31:e439-42.

20. Chen DS, Mellman I. Oncology meets immunology: the cancerimmunity cycle. Immunity. 2013;39:1-10.

21. Pardoll DM. The blockade of immune checkpoints in cancer immunotherapy. Nat Rev Cancer. 2012;12:252-64.

22. Grewal IS, Flavell RA. CD40 and CD154 in cell-mediated immunity. Annu Rev Immunol. 1998;16:111-35.

23. Zippelius A, Schreiner J, Herzig P, Muller P. Induced PD-L1 expression mediates acquired resistance to agonistic anti-CD40 treatment. Cancer Immunol Res. 2015;3:236-44.

24. Peach RJ, Bajorath J, Naemura J, Leytze G, Greene J, Aruffo A, et al. Both extracellular immunoglobin-like domains of CD80 contain residues critical for binding $\mathrm{T}$ cell surface receptors CTLA-4 and CD28. J Biol Chem. 1995;270:21181-7.

25. Walker LS, Sansom DM. The emerging role of CTLA4 as a cellextrinsic regulator of $\mathrm{T}$ cell responses. Nat Rev Immunol. 2011;11:852-63.

26. Lenschow DJ, Zeng Y, Thistlethwaite JR, Montag A, Brady W, Gibson MG, et al. Long-term survival of xenogeneic pancreatic islet grafts induced by CTLA4lg. Science. 1992;257:789-92.

27. Linsley PS, Wallace PM, Johnson J, Gibson MG, Greene JL, Ledbetter JA, et al. Immunosuppression in vivo by a soluble form of the CTLA-4 $\mathrm{T}$ cell activation molecule. Science. 1992;257:792-5.

28. Parsa AT, Waldron JS, Panner A, Crane CA, Parney IF, Barry JJ, et al. Loss of tumor suppressor PTEN function increases B7-H1 expression and immunoresistance in glioma. Nat Med. 2007;13:84-8.

29. Spranger S, Spaapen RM, Zha Y, Williams J, Meng Y, Ha TT, et al. Up-regulation of PD-L1, IDO, and T(regs) in the melanoma tumor microenvironment is driven by CD8(+) T cells. Sci Transl Med. 2013;5:200ra116. 